\title{
Docosahexaenoic acid (DHA): a modulator of microglia activity and dendritic spine morphology
}

\author{
Philip K-Y Chang ${ }^{1}$, Armen Khatchadourian' ${ }^{1}$, Rebecca Anne McKinney ${ }^{1,2^{*}}$ and Dusica Maysinger ${ }^{1 *}$
}

\begin{abstract}
Background: Recent studies have revealed that excessive activation of microglia and inflammation-mediated neurotoxicity are implicated in the progression of several neurological disorders. In particular, chronic inflammation in vivo and exposure of cultured brain cells to lipopolysaccharide (LPS) in vitro can adversely change microglial morphology and function. This can have both direct and indirect effects on synaptic structures and functions. The integrity of dendritic spines, the postsynaptic component of excitatory synapses, dictates synaptic efficacy. Interestingly, dysgenesis of dendritic spines has been found in many neurological diseases associated with $\omega-3$ polyunsaturated fatty acid (PUFA) deficiency and cognitive decline. In contrast, supplemented $\omega$-3 PUFAs, such as docosahexaenoic acid (DHA), can partly correct spine defects. Hence, we hypothesize that DHA directly affects synaptic integrity and indirectly through neuron-glia interaction. Strong activation of microglia by LPS is accompanied by marked release of nitric oxide and formation of lipid bodies (LBs), both dynamic biomarkers of inflammation. Here we investigated direct effects of DHA on synaptic integrity and its indirect effects via microglia in the hippocampal CA1 region.
\end{abstract}

Methods: Microglia (N9) and organotypic hippocampal slice cultures were exposed to the proinflammagen LPS (100 $\mathrm{ng} / \mathrm{ml}$ ) for $24 \mathrm{~h}$. Biochemical and morphological markers of inflammation were investigated in microglia and CA1 regions of hippocampal slices. As biomarkers of hyperactive microglia, mitochondrial function, nitric oxide release and LBs (number, size, LB surface-associated proteins) were assessed. Changes in synaptic transmission of CA1 pyramidal cells were determined following LPS and DHA (25-50 $\mu \mathrm{M})$ treatments by recording spontaneous AMPA-mediated miniature excitatory postsynaptic currents (mEPSCs).

Results: Microglia responded to LPS stimulation with a significant decrease of mitochondrial function, increased nitric oxide production and an increase in the formation of large LBs. LPS treatment led to a significant reduction of dendritic spine densities and an increase in the AMPA-mediated mEPSC inter-event interval (IEI). DHA normalized the LPS-induced abnormalities in both neurons and microglia, as revealed by the restoration of synaptic structures and functions in hippocampal CA1 pyramidal neurons.

Conclusion: Our findings indicate that DHA can prevent LPS-induced abnormalities (neuroinflammation) by reducing inflammatory biomarkers, thereby normalizing microglia activity and their effect on synaptic function.

Keywords: Docosahexaenoic acid, Lipid bodies, Mitochondria, Microglia, Neuroinflammation, Dendritic spines

\section{Background}

Chronic activation of inflammatory signaling cascades in the brain can play a critical role in the development of many neurodegenerative disorders [1]. This observation has led to investigations of the proinflammatory endotoxin lipopolysaccharide (LPS) and anti-inflammatory

\footnotetext{
* Correspondence: anne.mckinney@mcgill.ca; dusica.maysinger@mcgill.ca 'Department of Pharmacology and Therapeutics, McGill University, McIntyre Medical Building, Room 1314, 3655 Promenade Sir William Osler, Montreal, QC H3G 1Y6, Canada

Full list of author information is available at the end of the article
}

component of healthy diets rich in docosahexanoic acid (DHA) $[2,3]$ to reduce the deleterious effects of inflammation $[4,5]$. DHA, a $\omega-3$ polyunsaturated fatty acid ( $\omega-3$ PUFA), is abundant in the healthy brain, and it is enriched in the health-improving Mediterranean diets $[2,6,7]$. Randomized controlled studies with the nutritional supplement Souvenaid (containing DHA) suggest some functional improvements in a subpopulation of patients with the symptoms of mild Alzheimer's disease $[8,9]$. However, there are still some inconsistencies

\section{Biomed Central}

(c) 2015 Chang et al.; licensee BioMed Central. This is an Open Access article distributed under the terms of the Creative Commons Attribution License (http://creativecommons.org/licenses/by/4.0), which permits unrestricted use, distribution, and reproduction in any medium, provided the original work is properly credited. The Creative Commons Public Domain Dedication waiver (http://creativecommons.org/publicdomain/zero/1.0/) applies to the data made available in this article, unless otherwise stated. 
in findings from clinical and pre-clinical studies with DHA as a therapy in neurological diseases, in particular Alzheimer's disease [10]. The inconsistencies reported between the studies could be due to the inherent complexity of many neurological disorders, the diversity of populations used in different trials, different dosages and formulations, the stage of the disease when treatment began and other confounding factors $[11,12]$. In this article we set out to determine, in a simplified system, how DHA modulates inflammatory responses in N9 microglia and the hippocampus.

During inflammation, microglia, the resident immune cells in the brain, play a pivotal role in cerebral functions and act as major guardians of brains threatened by pathogens and the proinflammatory endotoxins they produce [13-16]. Recent studies revealed that microglia can also play a role in synaptic remodeling and plasticity in the healthy brain [17-20]. For example, microglia within the visual cortex can modify their association with dendritic spines in response to changes in visual sensory experience [21].

We selected to activate microglia by inducing inflammation using the most potent and commonly used proinflammatory stimulus, LPS, an endotoxin produced by gram-negative bacteria [22]. Hyperactive microglia produce and release inflammatory cytokines that can adversely affect synaptic structure [23,24]. Aside from known production of proinflammatory cytokines and nitric oxide, LPS-stimulated microglia form lipid bodies (LBs), organelles often found in macrophages exposed to infectious microorganisms or their endotoxins. LBs are organelles found in almost all eukaryotic cells, and their number and size vary in different cell types $[25,26]$. LBs were thought for many years to be storage sites for lipids; now they are beginning to emerge as dynamic organelles and signaling platforms affecting cell fate $[27,28]$. However the exact role of LBs in neural cell survival and maintenance of neural circuitries is unclear. Intriguingly, $\omega-3$ PUFAs, such as DHA, can be temporarily stored in LBs and become available to alter excitatory synapse morphology and function. The mechanism of DHA effects on postsynaptic dendritic spines is currently unclear. To examine changes in synaptic structures we concentrated on dendritic spines, the postsynaptic structural components found on excitatory synapses of principal neurons in the brain [29-32]. These structures contain the molecular machineries necessary for synaptic transmission and can directly dictate the efficacy of neurocircuits $[33,34]$. Spines have the ability to respond to learning paradigms by changing their number and size [32,33,35]. Therefore, it has been proposed that these structures are the morphological correlates for cellular models of learning and memory [36,37]. In fact, dendritic spine dysgenesis is found in many neurological disorders accompanied with cognitive deficits [29,38-40].

In this study we sought to investigate how DHA modulates hyperactive microglia and synaptic function in hippocampal CA1 neurons. We paid particular attention to LBs and showed that they can play a protective role when neural cells are treated with DHA. The results also show that DHA prevented dendritic spine loss and an increase in AMPA-mediated miniature excitatory postsynaptic current (mEPSC) inter-event intervals (IEI) in hippocampal CA1 pyramidal neurons when exposed to inflammatory agents.

\section{Methods}

Organotypic hippocampal slice cultures and treatment

Organotypic hippocampal slice cultures were prepared as previously described [41]. Briefly, the slice cultures were prepared from P6-8 transgenic mice that expressed membrane-targeted eGFP under the Thy-1 promoter in a subpopulation of CA1 neurons. Following decapitation, hippocampi were dissected; $400-\mu \mathrm{m}$-thick transverse slices were made and adhered onto glass coverslips with chicken plasma clot (Cocalico Biologicals; Reamstown, PA, USA). Cultures were maintained in a roller drum incubator at $36^{\circ} \mathrm{C}$ for 3 weeks prior to experimentation to allow for maturation. Culture medium consisted of $25 \%$ heatinactivated horse serum (Invitrogen GIBCO), 25\% Hank's balanced salt solution (Invitrogen GIBCO) and 50\% Basal Medium Eagle (Invitrogen GIBCO) and was replaced weekly. Once ready, the cultures were incubated in serum-free medium overnight and treatments (LPS, $10 \mu \mathrm{g} / \mathrm{ml}$; DHA, $25 \mu \mathrm{M}$; LPS + DHA) were applied for $24 \mathrm{~h}$. In the case of LPS + DHA, DHA was prepared as DHA/BSA complex (detailed preparation method below) and was added to the cultures as a pretreatment supplementation overnight prior to the addition of LPS. All animal care and treatment procedures were performed in accordance with guidelines set by the Canadian Council on Animal Care and McGill Animal Welfare Committee.

\section{DHA/BSA complex preparation}

DHA/BSA complex (hereafter referred to as DHA treatment) was prepared by adding $25 \mathrm{mg}$ of DHA (Nu-Check Prep) to $\sim 20 \mathrm{ml}$ of fatty acid-free BSA solution $(5 \% \mathrm{w} / \mathrm{v}$, in KRBH buffer; Sigma-Aldrich). The DHA/BSA solution was incubated for $5 \mathrm{~h}$ at $37^{\circ} \mathrm{C}$. After the incubation, the $\mathrm{pH}$ of the solution was adjusted to $\mathrm{pH} 7.4$, and the solution was filtered through a $0.22-\mu \mathrm{m}$ filter. The nonesterified DHA concentration in the solution was determined with the non-esterified fatty acid (NEFA) C method kit (Wako). The final molar ratio of DHA to BSA was approximately 6:1. Aliquots of the stock solution were flushed with argon to prevent oxidation of 
DHA and were stored at $-80^{\circ} \mathrm{C}$. In addition, the presence of BSA was controlled for in those cultures that did not receive the DHA treatment.

\section{Immunohistochemical staining of microglia lipid bodies and cytochrome c}

Following treatment, hippocampal slice cultures were removed from the cover glass and fixed in $0.1 \mathrm{M}$ phosphate buffer (PB) containing 4\% paraformaldehyde overnight at $4^{\circ} \mathrm{C}(\mathrm{pH}$ 7.4). After fixation, the cultures were washed in $0.1 \mathrm{M} \mathrm{PB}$, permeablized in $0.4 \%$ Triton X-100 and blocked with $1.5 \%$ heat-inactivated horse serum overnight at $4^{\circ} \mathrm{C}$. Primary antibodies were incubated for 5 days at $4^{\circ} \mathrm{C}$ in the permeablizing solution at a $1: 400$ dilution for ionized calcium-binding adapter molecule-1 (Iba-1) (Wako Chemicals USA, Inc., Richmond, VA, USA) and 1:400 dilution for perilipin-2/adipophilin (Plin-2/ADRP; PROGEN Biotechnik GmbH., Heidelberg Germany), 1:400 dilution for perilipin 2(ADRP; PROGEN Biotechnik GmbH., Heidelberg Germany) and 1:400 dilution for cytochrome $c$ (BD Pharmigen, Mississauga, Ontario, Canada). Secondary antibodies, DyLight 549 and 649 (Jackson ImmunoResearch Laboratories Inc., West Grove, PA, USA), were prepared at 1:250 dilutions in $0.1 \mathrm{M} \mathrm{PB}$ containing $1.5 \%$ heat-inactivated horse serum and incubated overnight. Slices were then mounted with DAKO Fluorescent Mounting medium (Dako Canada, Mississauga, Ontario, Canada) onto microscope slides prior to imaging and subsequent blinded analysis.

\section{Confocal microscopy and quantification}

Fluorescently labeled microglia and eGFP-expressing CA1 pyramidal neurons were imaged. For labeled microglia, the images were acquired using an upright Leica TCS SP2 confocal microscope (Leica Microsystems, Heidelberg, Germany) equipped with an HCX PL APOCHROMAT $63 \times$ NA 1.4 oil-immersion objective. Image stacks were collected at $\mathrm{Z}=0.25 \mu \mathrm{m}$ and averaged four times. Image stacks were deconvolved with Huygens Essentials software (Scientific Volume Imaging, Hilversum, The Netherlands) using a full maximum likelihood extrapolation algorithm. Three-dimensional volume rendering and LB size quantification were carried out with Imaris 7.0.0 software (Bitplane, Zurich, Switzerland). LBs were further categorized into small (diameter $<0.5 \mu \mathrm{m}$ ), medium (diameter $>0.5 \mu \mathrm{m}$ and $<1.0 \mu \mathrm{m}$ ) or large (diameter $>1.0 \mu \mathrm{m}$ ) for their distribution comparisons using the Spot function in the Imaris software.

For dendritic spine analysis, the images were acquired using a Zeiss LSM 710 confocal microscope (Carl Zeiss MicroImaging $\mathrm{GmbH}$ ) with a W Plan-APOCHROMAT $63 \times / 1.0$ objective. Either eGFP-expressing secondary or tertiary dendritic branches from either apical or basal dendrites were imaged. Dendritic spine quantification was also carried out using Imaris software (Bitplane). Dendritic spines were classified into three main subtypes, stubby, mushroom and thin-type spines, using previously established methods based on the morphological measurements of the spine head and neck diameters [42].

\section{Mitochondrial functional analysis with JC-1}

Following treatment, the slice cultures were examined for mitochondrial depolarization using the JC-1 dye (5,5',6,6' 'tetrachloro-1,1',3,3' 'tetraethylbenzimidazolylcarbocyanine iodide; Life Technologies, Burlington, Ontario, Canada), a positively charged cationic dye that exhibits membrane potential-dependent accumulation in mitochondria indicated by a fluorescence emission shift from red $(\sim 590 \mathrm{~nm})$ to green $(\sim 525 \mathrm{~nm})$. Slice cultures were incubated with $15 \mu \mathrm{M}$ of JC-1 for $45 \mathrm{~min}$ at $36^{\circ} \mathrm{C}$. Following incubation, slices were transferred to a temperature-controlled perfusion chamber mounted on an upright microscope (Carl Zeiss MicroImaging $\mathrm{GmbH}$ ) with a W Plan-APOCHROMAT $63 \times / 1.0$ objective and continuously perfused with Tyrode solution containing (in $\mathrm{mM}$ ): $\mathrm{NaCl}, 137 ; \mathrm{KCl}, 2.7 ; \mathrm{CaCl}_{2}, 2.5$; $\mathrm{MgCl}_{2}, 2 ; \mathrm{NaHCO}_{3}, 11.6 ; \mathrm{NaH}_{2} \mathrm{PO}_{4}, 0.4$; glucose, 5.6 ( $\mathrm{pH}$ 7.4). Images were acquired at $\mathrm{Z}=0.25 \mu \mathrm{m}$ and averaged four times. Image stacks were deconvolved with Huygens Essentials (Scientific Volume Imaging) and quantified using Imaris (Bitplane). Mean fluorescence intensity of the image stacks were measured separately in both the green and red channels.

\section{Electrophysiological recordings}

Slices were transferred into a temperature-controlled chamber $\left(30^{\circ} \mathrm{C}\right)$ mounted on an upright microscope (DM LFSA, Leica Microsystems) and continuously perfused with Tyrode solution. Patch and field recording electrodes were pulled from borosilicate glass (GC150TC; Clark Instruments, UK). All electrophysiological recordings were made using an Axopatch 200A amplifier (Molecular Devices, Sunnyvale, CA, USA). Littermate and sister cultures were used to eliminate potential interexperimental discrepancies. To record AMPA-mediated mEPSC, whole-cell voltage-clamp recordings from CA1 pyramidal neurons were obtained at $30^{\circ} \mathrm{C}$ using electrodes with resistances of 4-5 $\mathrm{M} \Omega$ and filled with intracellular solution containing (in mM): K-gluconate, 120; EGTA, 1; HEPES, 10; Mg-ATP, 5; Na-GTP 0.5; NaCl, 5; KCl, 5; phosphocreatine, 10; 295 mOsm; $\mathrm{pH}$ adjusted with $\mathrm{KOH}$ to 7.3. AMPA-mediated mEPSCs were recorded with $1 \mu \mathrm{M}$ tetrodotoxin (TTX), $15 \mu \mathrm{M} \mathrm{CPP}, 100 \mu \mathrm{M}$ picrotoxin and $1 \mu \mathrm{M}$ CGP55845 in the external Tyrode's solution at $-60 \mathrm{mV}$. Access resistance was monitored with brief test pulses at regular intervals $(2-3 \mathrm{~min})$ 
throughout the experiment. Access resistance was usually 10-13 $\mathrm{M} \Omega$, and data were discarded if the resistance deviated more than $20 \%$ through the course of the experiment. After the holding current had stabilized, data were recorded at a sampling frequency of $10 \mathrm{kHz}$ and filtered at $2 \mathrm{kHz}$ for 10 to $15 \mathrm{~min}$. All mEPSCs were detected offline using the Mini Analysis Software (Synaptosoft, Decatur, GA, USA). The amplitude threshold for mEPSC detection was set at four times the root-mean-square value of a visually event-free recording period. Every recording was selected for blinded analysis of IEI and amplitude. The data obtained were then used to plot cumulative histograms with an equal contribution from every cell. For statistical analysis, data were averaged for every single cell.

\section{Cell culture and treatments}

Murine immortalized microglia (N9) cells obtained from Dr. Seguela, (Montreal Neurological Institute) were seeded in Iscove's Modified Dulbeco's Medium (IMDM; Gibco) containing 5\% fetal bovine serum (Gibco) and $1 \%$ penicillin-streptomycin (Gibco). Cells were maintained at $37^{\circ} \mathrm{C}$ in a humidified atmosphere containing $5 \% \mathrm{CO}_{2}$. Adherent cells were treated with LPS $(100 \mathrm{ng} / \mathrm{ml}$; Sigma-Aldrich), DHA (50 $\mu \mathrm{M}$; Nu-Chek Prep).

\section{Measurement of mitochondrial metabolic activity in microglia N9 cells}

Mitochondrial metabolic activity in N9-treated cells was assessed by measuring the extent of thiazolyl blue tetrazolium bromide (MTT) (Sigma-Aldrich) reduction to formazan. Cells were seeded in 24-well plates (Sarstedt) at a density of $5 \times 10^{4}$ cells/well. Following treatments with DHA, or LPS or LPS and DHA for $24 \mathrm{~h}$, media were removed and replaced with serum-free media containing MTT $(0.5 \mathrm{mg} / \mathrm{ml})$. After $30 \mathrm{~min}$ of incubation at $37^{\circ} \mathrm{C}$, media were aspirated from each well, and formazan crystals were dissolved in dimethylsulfoxide (DMSO) (Sigma-Aldrich). The formazan obtained from the reduction of MTT was measured by using a Benchmark microplate reader (Bio-Rad) at $595 \mathrm{~nm}$. All measurements were done in triplicates, in three or more independent experiments.

\section{Lipid body (LB) labeling}

LBs in N9 cells fixed with 4\% paraformaldehyde were visualized with the neutral lipid staining fluorophores BODIPY 493/503 (4,4-difluoro-1,3,5,7,8-pentamethyl-4bora-3a,4a-diaza-s-indacene; Invitrogen) or HCS LipidTOX Deep Red (Invitrogen). Stock solution of BODIPY 493/503 (4 mM) was made by dissolving the powder in DMSO. Cells were incubated with BODIPY 493/503 (20 $\mu \mathrm{M}$, in PBS, $10 \mathrm{~min}$ ) or with HCS LipidTOX (1:200 in
PBS, $30 \mathrm{~min}$ ). Cells were washed with PBS prior to confocal imaging.

\section{Double labeling of mitochondria and LBs}

Live microglial cells were incubated with Mitotracker Deep Red 633 (500 nM) for $3 \mathrm{~min}$ at $37^{\circ} \mathrm{C}$. After a wash with sterile PBS, cells were incubated with BODIPY 493/ 503 (prepared in cultured media, $20 \mu \mathrm{M}$ ) for $10 \mathrm{~min}$ at $37^{\circ} \mathrm{C}$. Cells were washed with PBS and then incubated in culture media during the imaging session.

\section{Confocal microscopy of N9 cell cultures}

Images were acquired with a Zeiss LSM 510 NLO inverted confocal microscope using a Plan Achromat $63 \times 1.4$ N.A. Oil DIC objective. Microglial N9 cells were seeded at a density of $1 \times 10^{4}$ cells/well in confocal chamber slides (Lab-Tek, Nalge Nunc International) or on coverslips at a density of $1.5 \times 10^{4}$ cells/well. Coverslips were mounted on glass microscope slides (Fisher Scientific) using glycerol-free mounting media Vectashield $\mathrm{H}$ 1000 (Vector) and were sealed around the perimeter with clear nail polish. Images of BODIPY 493/503-labeled LBs were acquired by using the argon 488-nm excitation laser. Imaging of Mitotracker Deep Red 633-labeled mitochondria was done using an HeNe 633-nm excitation laser. Alexa Fluor 594 was detected using an HeNe 543 excitation laser. All images were acquired at a resolution of $1,024 \times 1,024$ pixels and a zoom factor of at least 1.5 . Zstack images consisted of 15 to 20 optical sections and were taken at intervals of $0.3 \mu \mathrm{m}$.

\section{Analysis of LB volume and number in N9 cell cultures}

Confocal images of fluorescently labeled LBs were analyzed using the Imaris software (Bitplane), similar to that described for the organotypic slice cultures.

\section{Western blot analysis}

Whole cell extracts were made by lysing the N9 cells in NP-40 buffer (50 mM Tris $\mathrm{pH} 8.0,137 \mathrm{mM} \mathrm{NaCl}, 1 \%$ NP-40, 10\% glycerol) and were supplemented with a complete protease inhibitor cocktail (1 tablet per $25 \mathrm{ml}$ of lysis buffer; Roche Applied Science) and with phosphatase inhibitors sodium orthovanadate $(1 \mathrm{mM})$ and sodium fluoride $(1 \mathrm{mM})$. Cell lysates were boiled in $6 \times$ sample buffer (12\% SDS, 30\% glycerol, $0.2 \%$ bromophenol blue, $12 \%$ 2-mercaptoethanol, $0.375 \mathrm{M}$ Tris $\mathrm{HCl} \mathrm{pH}$ 6.8) at a 5:1 (cell lysate:sample buffer) ratio for $5 \mathrm{~min}$, and proteins were resolved by SDS-PAGE and then transferred $(1 \mathrm{~h}, 100 \mathrm{~V}$, in ice-cold transfer buffer) to nitrocellulose membranes (Hybond, Amersham Bioscience). Blocking of the membranes was performed by incubating them in $5 \%$ milk or BSA (in TBS-T). Membranes were incubated with primary antibodies to perilipin-2 (ADRP) (1:500) (guinea pig polyclonal, Fitzgerald 
Ind. 20R-AP002), perilipin-3 (TIP47) (1:500) (guinea pig polyclonal, Progen GP30), p38 (rabbit polyclonal) (1:500) (Santa Cruz, sc-535), phospho-p38 (rabbit monoclonal) $(1: 1,000)$ (Cell Signaling \#9215) and actin (mouse monoclonal) $(1: 1,000)$ (Millipore, MAB1501R) overnight at $4^{\circ} \mathrm{C}$. Following incubation with primary antibodies, membranes were incubated with horseradish peroxidase-linked secondary antibodies anti-rabbit IgG (Amersham Biosciences, NA 934), anti-guinea pig IgG (Sigma, A5545) and antimouse IgG (GE Healthcare, NXA931). The binding of the secondary antibody to the primary antibody was visualized by using an ECL Plus detection kit and HyBlot autoradiography films (Denville). Films were scanned (gray scale at 16 bits), and relative intensities of the immunoreactive bands were analyzed using the gel analyzer tool in the Image J (1.42) software.

\section{Nitric oxide release}

Nitric oxide release was measured using Griess reagent (Sigma) according to the protocol provided by the supplier. Briefly, following treatment, culture media were collected, and Griess reagent was added and incubated at room temperature for 15-20 min. After incubation, absorbance of the nitrite produced was measured at $540 \mathrm{~nm}$ using a spectrophotometer. All experiments were performed twice, and measurements were made in triplicate.

\section{Statistical analysis}

All experiments were performed at least twice, and all samples were analyzed in triplicate. Data are expressed as mean \pm SEM and analyzed by ANOVA using the Tukey and Dunnett post hoc test for multiple comparisons. Significant differences are indicated by ${ }^{*} p<0.05$, ${ }^{* *} p<0.01$ and ${ }^{* * *} p<0.001$.

\section{Results}

In order to establish a working model of neuroinflammation, we used the microglial activator LPS, a commonly used proinflammatory agent. We optimized the concentration of LPS for inflammation by testing a range of LPS concentrations in N9 cultures for $24 \mathrm{~h}$ (Additional file 1: Figure S1A). Inflammation was assessed by the degree of microglia activation by measuring nitrite (an indicator of nitric oxide release). We found a highly significant increase in nitric oxide release with $100 \mathrm{ng} / \mathrm{ml}$ LPS without any further increase with higher $(1 \mu \mathrm{g} / \mathrm{ml})$ LPS concentrations (Additional file 1: Figure S1A; control: $3.84 \pm 0.26 \mu \mathrm{M} ; 100 \mathrm{ng} / \mathrm{ml}$ : $17.24 \pm 0.86 \mu \mathrm{M} ; 1 \mu \mathrm{g} / \mathrm{ml}: 17.51 \pm 0.44 \mu \mathrm{M} ; 10 \mu \mathrm{g} / \mathrm{ml}$ : $18.39 \pm 0.34 \mu \mathrm{M} ; p<0.05)$. Based on these findings, we chose to use either a low $(100 \mathrm{ng} / \mathrm{ml})$ or high $(1 \mu \mathrm{g} / \mathrm{ml})$ concentration of LPS to examine the formation of LBs after $24 \mathrm{~h}$ in both organotypic hippocampal slice cultures and N9 microglia cultures (Figure 1).
Next, we wanted to assess whether LPS induces changes in the activation of microglia by immunostaining of the biomarker for microglia activation, Iba-1. We revealed hypertrophic microglial morphology following LPS treatment at both high $(1 \mu \mathrm{g} / \mathrm{ml})$ and low (100 ng/ $\mathrm{ml}$ ) concentrations in organotypic hippocampal slice cultures, which contain both neurons and glia cells in situ (Figure 1A). Furthermore, in the same organotypic hippocampal culture system, both concentrations of LPS decreased the total number of LBs [control: $27.50 \pm 2.01$ LBs/cell, $n=13$ cells from 8 slices; LPS (100 ng/ml): $19.4 \pm 3.37 \mathrm{LBs} /$ cell, $n=21$ cells from 11 slices; LPS $(1 \mu \mathrm{g} / \mathrm{ml}): 9.91 \pm 2.26 \mathrm{LBs} /$ cell, $n=11$ cells from 6 slices]. When the size of LBs was examined, there was a decreased number of small $(<0.5 \mu \mathrm{m})$ LBs in microglia [control: $21.60 \pm 1.93 \mathrm{LBs} /$ cell; LPS (100 $\mathrm{ng} / \mathrm{ml}): 2.14 \pm 0.81 \mathrm{LBs} /$ cell; LPS $(1 \mu \mathrm{g} / \mathrm{ml}): 1.45 \pm$ $0.72 \mathrm{LBs} /$ cell] and an increased number of large $(>1.0$ $\mu \mathrm{m})$ LBs [control: $0.07 \pm 0.07 \mathrm{LBs} /$ cell; LPS $(100 \mathrm{ng} / \mathrm{ml})$ : $11.71 \pm 1.50 \mathrm{LBs} /$ cell; LPS $(1 \mu \mathrm{g} / \mathrm{ml}): 5.09 \pm 1.33 \mathrm{LBs} / \mathrm{cell}]$. Similarly, LPS treatments of N9 microglia increased the number of large LBs (Figure 1C-E; control: $3.62 \pm 0.87$ LBs/cell; LPS: $16.43 \pm 2.01 \mathrm{LBs} /$ cell; $p<0.05$ ). These findings suggest that formation of the larger sized LBs is a hallmark of microglial inflammatory response in either microglia in the absence of neurons or in intact slice cultures containing both neurons and glia in situ.

As it has been suggested previously that DHA and its derivatives have protective effects against inflammation, we examined whether the addition of DHA $(25 \mu \mathrm{M})$ to organotypic slice cultures overnight $(\sim 16 \mathrm{~h})$ prior to LPS treatment could prevent the LPS-induced changes of microglial morphology. We found that DHA alone did not change the appearance of microglia in the slice cultures when compared to control slices (Figure 2A). Interestingly, in those slices that were treated with DHA and $100 \mathrm{ng} / \mathrm{ml}$ of LPS, there was no observed microglial hypertrophy as seen with LPS treatment alone (Figure 2A). However, at higher concentrations of LPS $(1 \mu \mathrm{g} / \mathrm{ml})$, the addition of DHA did not prevent microglia from becoming hypertrophic in the presence of LPS (Figure 2A). This suggested that while DHA may have a protective role against lower grade neuroinflammation, this effect did not appear to be extended into more severe inflammation. We also investigated whether DHA supplementation can lead to a change in the number and size of LBs during neuroinflammatory response induced by LPS at the two concentrations. When we analyzed LB distributions in the labeled microglia, we found that the addition of DHA returned total LB numbers to the control level in both low [Figure 3B; control: $36.80 \pm 3.98 \mathrm{LBs} /$ cell, $n=18$ cells from 10 slices; DHA: $46.40 \pm 6.33 \mathrm{LB} /$ cell; $n=20$ cells from 10 slices; LPS (100 ng/ml) + DHA: $39.10 \pm 4.51 \mathrm{LBs} /$ cell, $n=21$ cells from 11 slices] and high concentrations 


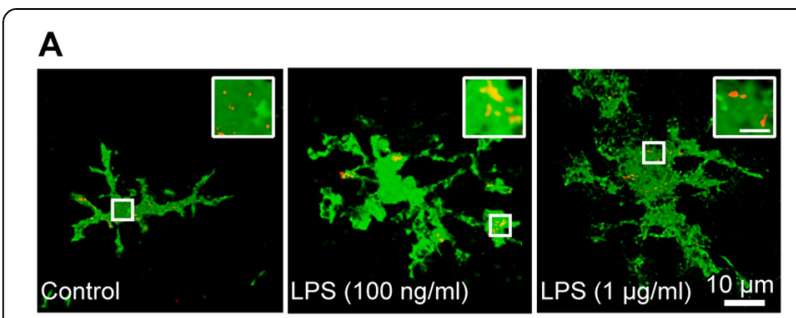

B

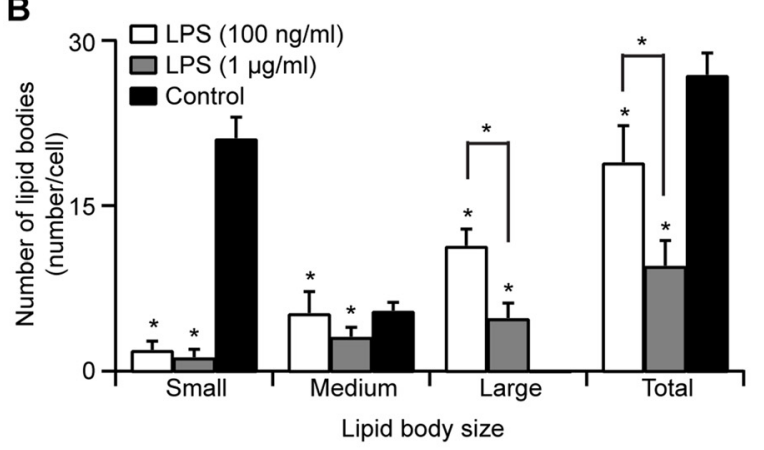

C
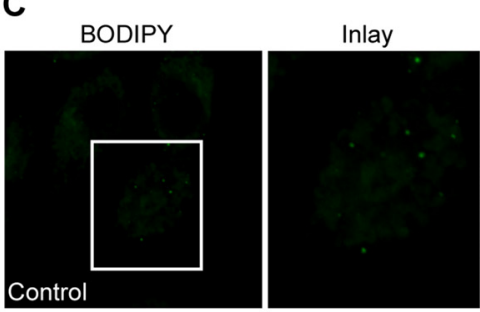

Phase contrast
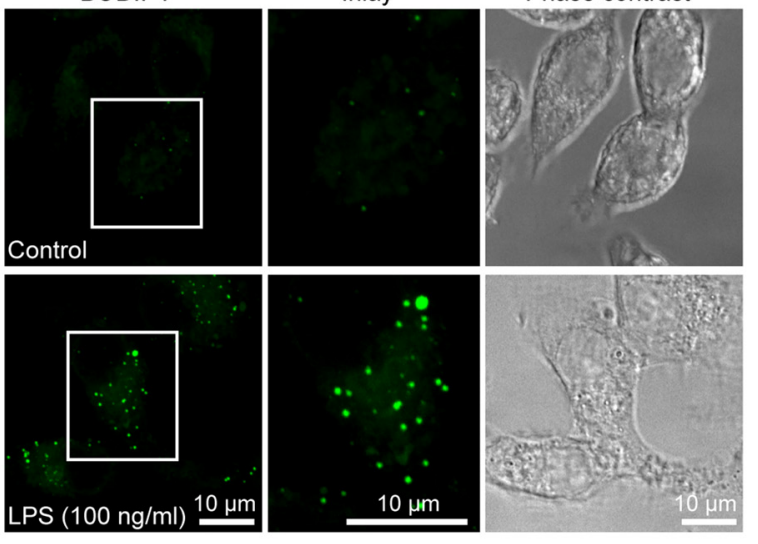

D

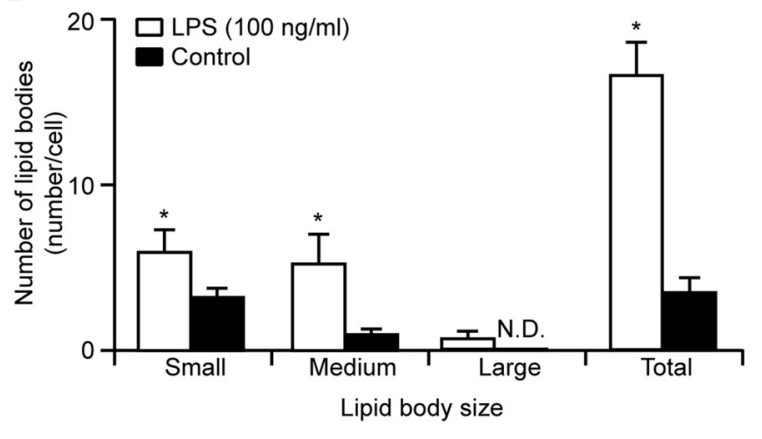

Figure 1 LPS treatment alters LB number, increases LB size and causes microglia hypertrophy in organotypic hippocampal slice cultures and N9 microglial cells. A Examples of LB formation in microglia from control and treated slices. In the presence of LPS $(100 \mathrm{ng} / \mathrm{ml}$ or $1 \mu \mathrm{g} / \mathrm{ml})$, more larger $(>1.0 \mu \mathrm{m})$ LBs are present compared to control conditions. Microglial morphologies are also more ramified and appear to be more activated in the LPS-treated cultures. Scale bar $10 \mu \mathrm{m}$. Green, Iba-I. Red, ADRP. B LB density under various treatments with various $L B$ sizes in microglia. ${ }^{*} p<0.05$. C Examples of LB formation in N9 microglial cells showing that LPS treatment altered LB distribution. Following LPS treatment, there is an increase in LB formation. $\mathbf{D}$ LB densities and sizes following LPS treatment, showing that there is an increase in the large-sized LBs. ${ }^{*} p<0.05$.

of LPS treatment [Figure 2B; LPS $(1 \mu \mathrm{g} / \mathrm{ml})+$ DHA: $30.11 \pm 2.26 \mathrm{LBs} /$ cell, $n=19$ cells from 9 slices]. Upon closer examination of the different-sized LBs, we found that DHA prevented the appearance of the large $(>1.0$ $\mu \mathrm{m})$ LBs that were seen after low [Figure 2B; control: $0.017 \pm 0.090 \mathrm{LBs} /$ cell; DHA: $0.00 \pm 0.00 \mathrm{LB} /$ cell; LPS $(100 \mathrm{ng} / \mathrm{ml})+$ DHA: $0.00 \pm 0.00 \mathrm{LBs} /$ cell $]$ and high LPS treatments [Figure 3B; LPS $(1 \mu \mathrm{g} / \mathrm{ml})+$ DHA: $0.21 \pm$ $0.034 \mathrm{LBs} / \mathrm{cell}]$. There was also an increase in small-sized LBs $(<0.5 \mu \mathrm{m})$, comparable to that of the control in DHA and LPS $(100 \mathrm{ng} / \mathrm{ml})+$ DHA-treated cultures [Figure 3B; control: $27.00 \pm 4.19 \mathrm{LBs} /$ cell; DHA: $39.45 \pm 6.13 \mathrm{LB} /$ cell; LPS $(100 \mathrm{ng} / \mathrm{ml})+$ DHA: $30.30 \pm 3.63 \mathrm{LBs} /$ cell]. However, in the $1 \mu \mathrm{g} / \mathrm{ml}$ LPS treatment, there were fewer small [Figure 2B; LPS $(1 \mu \mathrm{g} / \mathrm{ml})+$ DHA: $14.03 \pm 2.27 \mathrm{LBs} /$ cell] and more medium-sized LBs $(>0.5 \mu \mathrm{m}$ and $<1.0 \mu \mathrm{m})$ in microglia [Figure 3B; control: $9.67 \pm 1.72 \mathrm{LBs} /$ cell; DHA: $6.55 \pm 1.32 \mathrm{LB} /$ cell; LPS $(100 \mathrm{ng} / \mathrm{ml})+$ DHA: $8.10 \pm 2.65$ LBs/cell; LPS $(1 \mu \mathrm{g} / \mathrm{ml})+$ DHA: $15.84 \pm 2.56 \mathrm{LBs} / \mathrm{cell}]$. This suggested that DHA prevented the LPS-induced changes in LB and microglia morphology after exposure to lower concentrations of LPS. Interestingly, at the higher LPS concentration, DHA did not prevent the hypertrophic microglia, but did prevent the formation of large-sized LB formation.

In order to establish how the addition of DHA could prevent changes in microglia and LBs, we examined the impact of adding DHA $(25 \mu \mathrm{M})$ to microglial N9 cultures prior to the treatment with LPS using further biochemical analysis to ensure that we were only measuring the biochemical changes found within microglial cells and not other cell types typically found in slice cultures, such as neurons and astrocytes. We found that although both LPS and DHA significantly increased the number of LBs in microglial cells, the increase was much more pronounced in cells exposed to DHA ( $\sim 37$ fold), while there was only a modest increase following LPS alone ( $\sim 5$ fold) treatment (Figure 3A-C). We also found that the addition of LPS to cells exposed to DHA significantly reduced the LB number/cell $(p<0.05)$ compared 


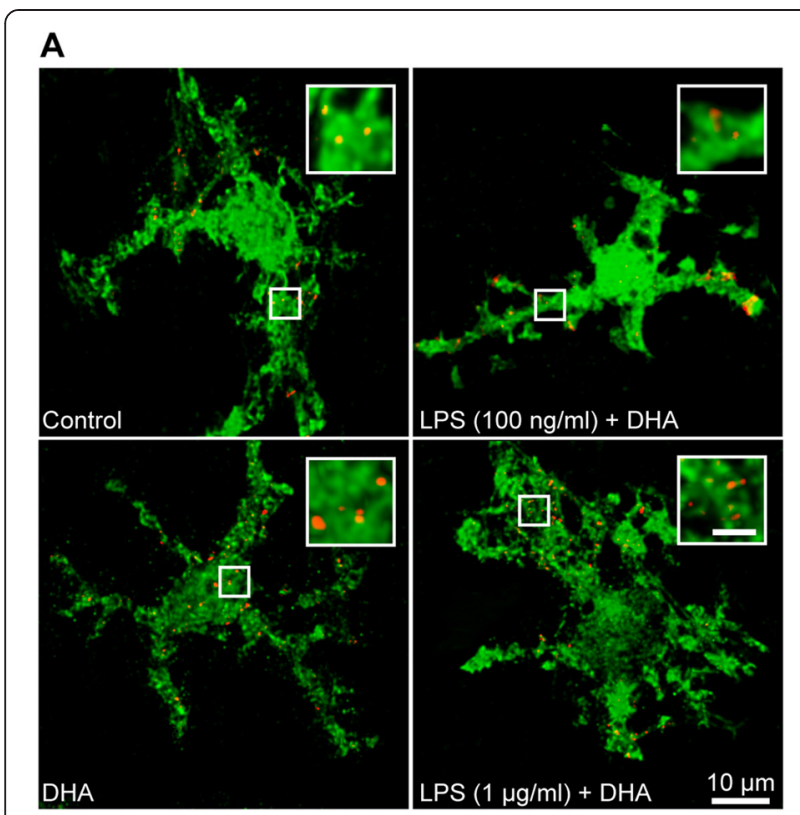

B

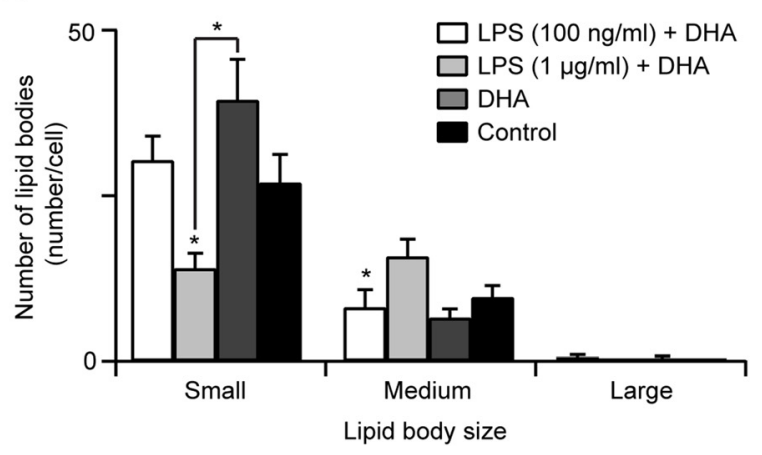

Figure 2 DHA promotes small LB formation and normalizes LPS-induced microglial hypertrophy. A Examples of activated microglial morphologies and LB formation from control and treated organotypic hippocampal slice cultures. In the presence of DHA, more small $(<0.5 \mu \mathrm{m})$ LBs are present compared to other conditions. In LPS-treated cultures, the activated microglia contain fewer LBS compared to others. Arrows indicate small LBs; triangles indicate larger LBs. Scale bar $10 \mu \mathrm{m}$. Green, Iba-I. Red, ADRP. B LB density under various treatments with various $L B$ sizes in microglia. ${ }^{*} p<0.05$.

to cells treated with DHA alone (Figure 3A and B). Our reconstruction of the individual confocal Z-stack images of fluorescently labeled LBs and subsequent quantification of LB volumes revealed that an exposure of microglial cultures to LPS led to a significant increase in the average volume of LBs (control: $0.05 \pm 0.011 \mu^{3}$; DHA: $0.183 \pm 0.02 \mu \mathrm{m}^{3}$; LPS: $0.104 \pm 0.016 \mu \mathrm{m}^{3}, p<0.01$ ). Treatment with LPS may have slightly reduced the relative abundance of small LBs $(-14.9 \% ; p>0.05)$ and concomitantly increased the proportion of medium-sized LBs $(+13.2 \% ; p>0.05)$ in microglial cells, but this was not significant.
Next, we investigated whether there were changes in LB-associated proteins essential for LB stability, growth and proliferation, namely perilipin-2 (ADRP) and perilipin-3 (TIP47) [43,44]. We performed Western blotting to compare how LPS and DHA influenced the levels of perilipin-2 and -3 in microglial cells (Figure 3D and E). Exposure of microglia to LPS alone led to a rise in the level of perilipin-2 associated with the accumulation of LBs $[45,46]$. DHA alone significantly increased the level of perilipin-2 ( 17 fold; $p<0.001)$; this increase was considerably higher than that observed in microglial cells exposed to LPS alone ( 3 fold; $p<0.05$ ). In contrast, neither DHA nor LPS caused a significant change in the level of perilipin-3 in microglia. We also investigated how LPS influenced the extent of p38 kinase phosphorylation, as this kinase was implicated in LB generation. Western blot analysis revealed that exposure of microglial cells to LPS alone caused a transient increase in p38 phosphorylation that reached a maximum 15 min post LPS treatment (Figure 3F and G). Interestingly, DHA treatment of N9 microglia significantly reduced LPS-induced p38 activation (Figure 3F and G). DHA alone also induced p38 phosphorylation, but to a lesser extent than LPS (Additional file 1: Figure S2; $n=6$; $" p<0.05$ ). We also found that DHA in the presence of LPS led to a significant reduction in nitric oxide production, suggesting a reduction in iNOS induction (Additional file 1: Figure S1B; control, $0.67 \pm 0.12 \mu \mathrm{M}$; LPS, $34.33 \pm 0.49 \mu \mathrm{M}$; DHA, $0.94 \pm 0.093 \mu \mathrm{M}$; LPS + DHA, $22.4 \pm 0.51 \mu \mathrm{M}$. Control, $n=6$; LPS, $n=6$; DHA, $n=5$; LPS + DHA, $n=5$; * $p<0.05)$.

LBs have been previously shown to form membrane contact sites with different organelles, including mitochondria $[47,48]$. The substantial changes in the number, volume and size distribution of LBs that we observed in microglial cells exposed to LPS and to DHA, or to their mixture, prompted us to examine possible LBmitochondria contacts. Using confocal microscopy, we found that LBs and mitochondria are often found close to each other in microglial cells exposed to DHA or to DHA and LPS combined, but not to LPS alone. This was seen in both pure microglial and organotypic hippocampal slice cultures (Figure 4A and C). Smaller LBs may be more mobile and presumably more effective in providing energy to mitochondria. DHA-induced LB in N9 microglia restored the defective mitochondrial metabolism caused by LPS (Figure 4B; control: $100.00 \pm 1.10 \%$; LPS + DHA: $95.5 \pm 1.80 \% ; p>0.05$; Figure 4B; LPS: $52.70 \pm 2.40 \% ; p<0.05)$. In support of this finding in N9 microglia, JC-1 staining for mitochondrial membrane potential in CA1 region of organotypic hippocampal slice cultures revealed that DHA treatment also restored the mitochondrial deficits caused by LPS treatment (Figure 4D; control: $1.48 \pm 0.14$; 


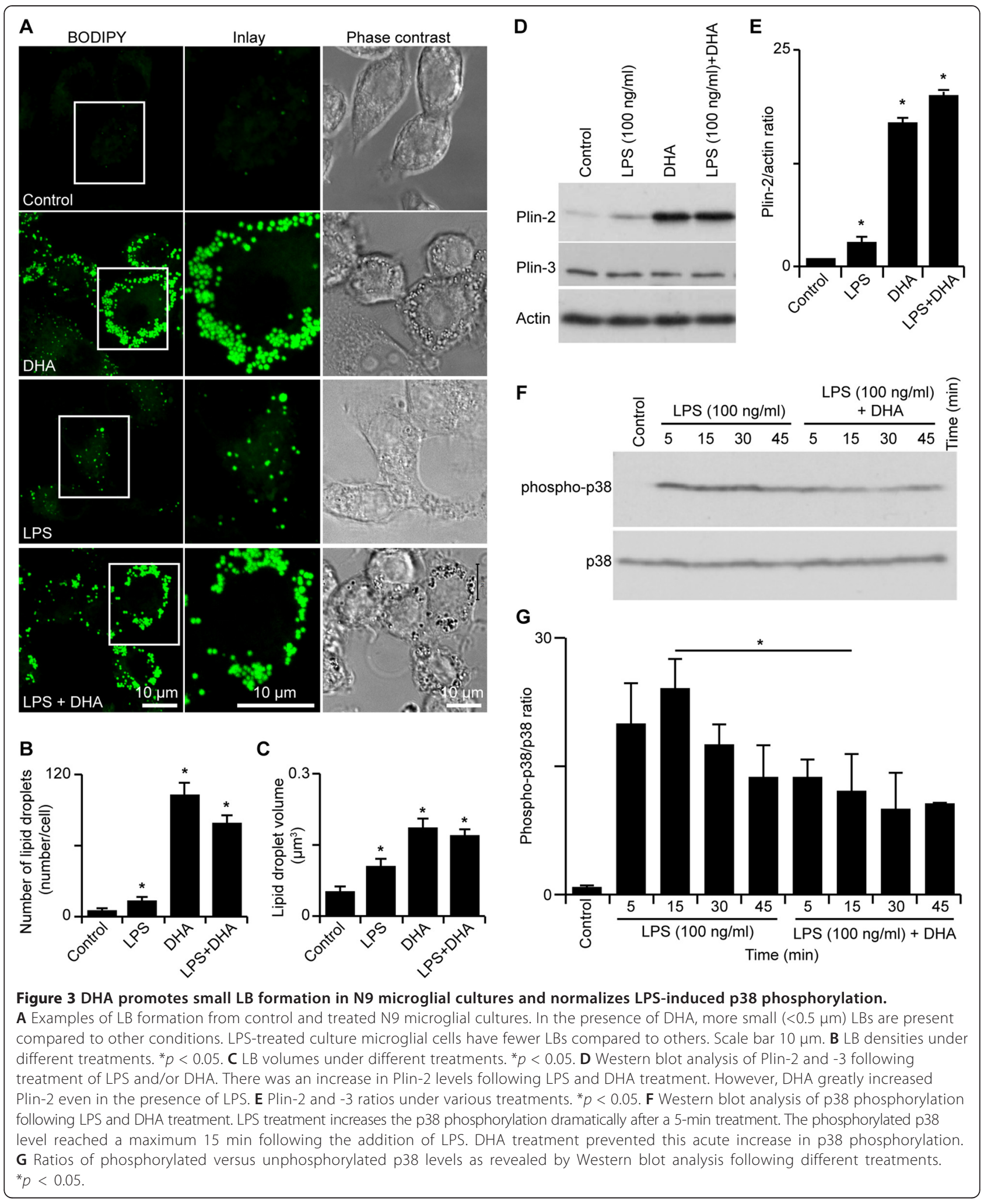

LPS: $1.09 \pm 0.055$; DHA: $1.48 \pm 0.11$; LPS + DHA: $1.38 \pm$ 0.078 ; * $p<0.05 ; n=12-15$ image stacks from $4-5$ cultures from each condition).
Since microglia activation and neuroinflammation have been implicated in various neurological disorders, we next wanted to assess the impact of LPS treatment 


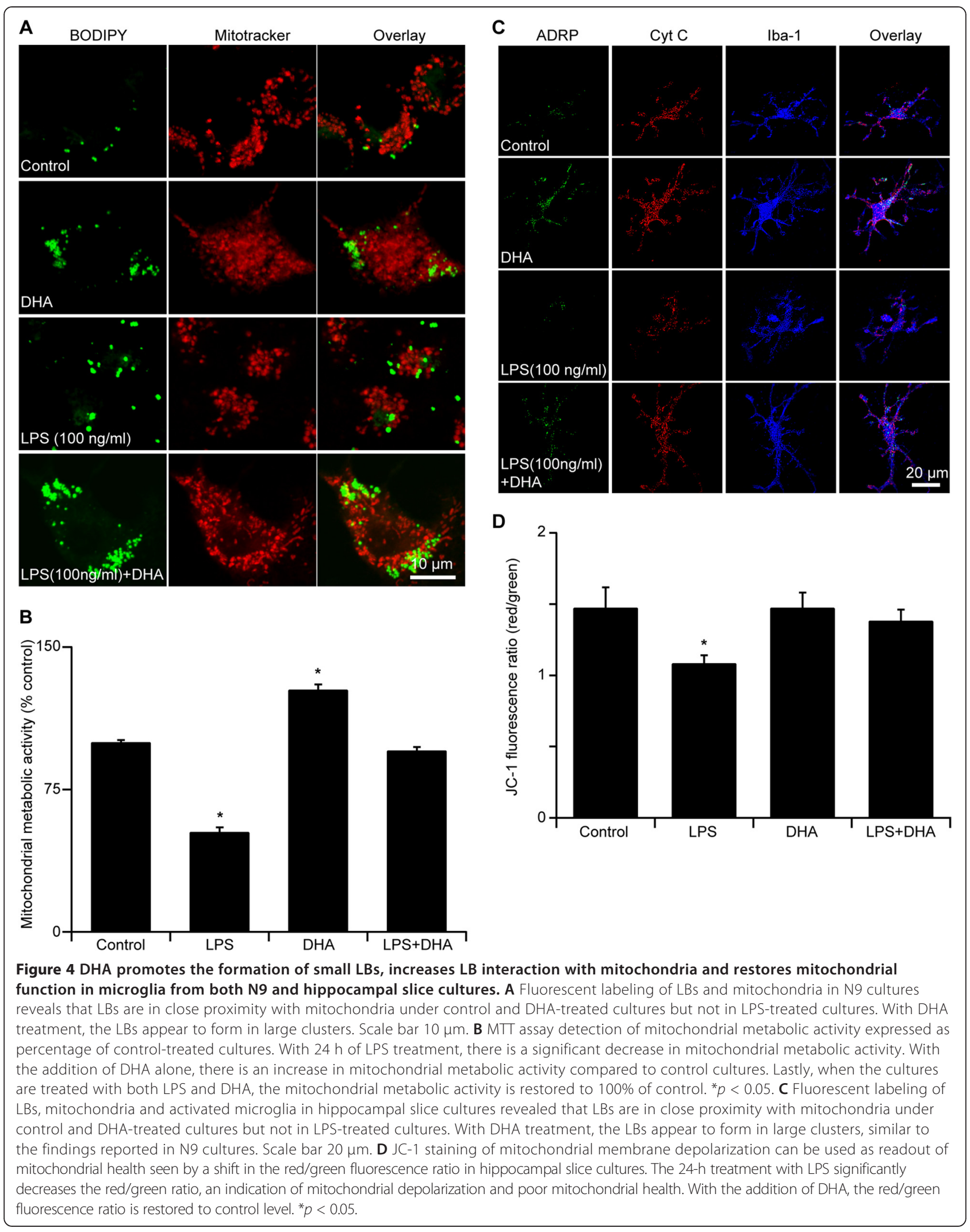


on synaptic structure by examining dendritic spines as their dysgenesis has been shown in many neuropathologies. As dendritic spines are the integral postsynaptic components of functional excitatory synaptic circuits, any compromise in their structures can negatively impact the normal physiology of the brain. With both low (100 ng/ml) or high $(1 \mu \mathrm{g} / \mathrm{ml})$ LPS concentrations, we found a significant decrease in total dendritic spine densities in CA1 pyramidal cells in hippocampal slice cultures [Figure 5; control: $1.67 \pm 0.11$ spines $/ \mu \mathrm{m}, n=25$ cells, 1-2; dendritic segment of 20-50 $\mu \mathrm{m}$ per cell; LPS $(100 \mathrm{ng} / \mathrm{ml}): 1.31 \pm 0.056$ spines $/ \mu \mathrm{m}, n=16$ cells; LPS $(1 \mu \mathrm{g} / \mathrm{ml}): 1.10 \pm 0.085$ spines $/ \mu \mathrm{m}, n=21$ cells]. The decrease in spine numbers could be attributed to the reduction of both larger, mushroom- [Figure 5; control: $0.63 \pm 0.062$ spines $/ \mu \mathrm{m} ;$ LPS $(100 \mathrm{ng} / \mathrm{ml}): 0.40 \pm 0.037$ spines $/ \mu \mathrm{m}$; LPS $(1 \mu \mathrm{g} / \mathrm{ml}): 0.40 \pm 0.037$ spines $/ \mu \mathrm{m}]$ and thin-type spines [Figure 5; control: $0.84 \pm 0.075$ spines/ $\mu \mathrm{m} ; \mathrm{LPS}(100 \mathrm{ng} / \mathrm{ml}): 0.58 \pm 0.039$ spines $/ \mu \mathrm{m} ; \mathrm{LPS}(1$ $\mu \mathrm{g} / \mathrm{ml}): 0.42 \pm 0.050$ spines $/ \mu \mathrm{m}]$. We found with the higher concentration of LPS, there was a further reduction in the number of thin spines resulting in a lower total spine count. As dietary DHA supplementation has been reported to suppress inflammation, we tested whether the addition of DHA in our system could prevent the damaging effects of LPS-induced inflammatory response. In slice cultures that were treated with DHA alone, we found no difference in spine density compared to control slices (Figure 5; total spine density, DHA: $1.53 \pm$ 0.099 spines $/ \mu \mathrm{m}, n=12$ cells; $p>0.05$ ). More importantly, at both high and low concentrations of LPS, the addition of DHA successfully prevented the dendritic spine decrease caused by LPS treatment, as there was no difference in spine densities between the LPS + DHA-treated and control cultures [Figure 5 ; total spine density: LPS $(1 \mu \mathrm{g} / \mathrm{ml})+$ DHA: $1.72 \pm 0.077$ spines $/ \mu \mathrm{m}, n=16$ cells; LPS $(1 \mu \mathrm{g} / \mathrm{ml})+$
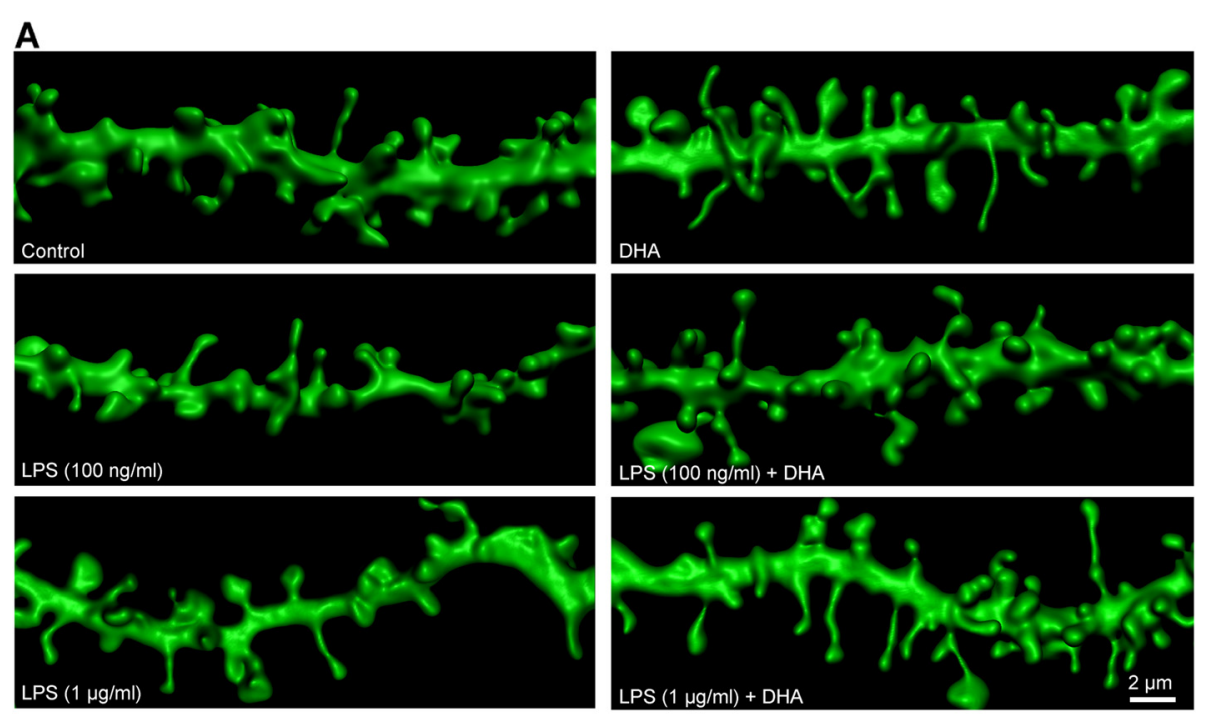

B

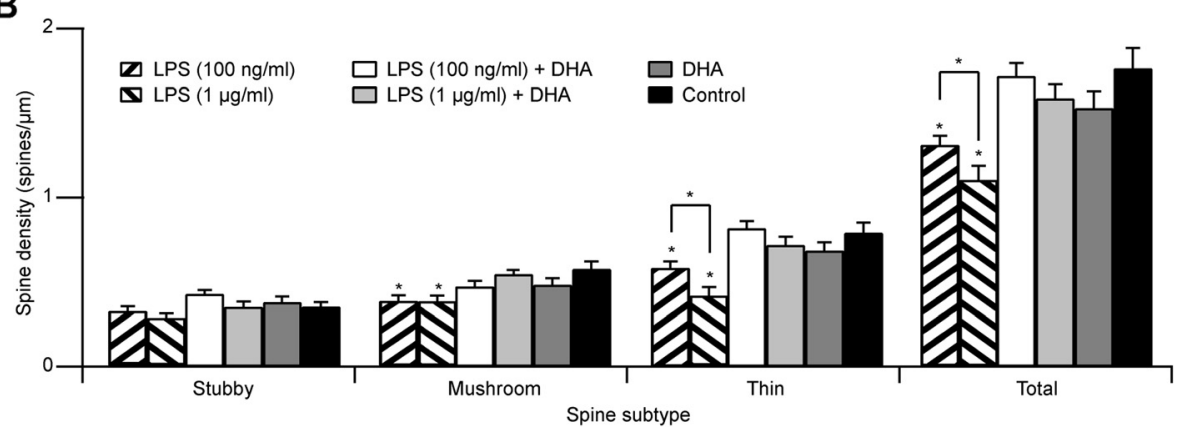

Figure 5 LPS treatment decreases dendritic spine densities of CA1 pyramidal neurons in organotypic hippocampal slice cultures that are prevented by DHA. A Examples of dendrites segments from CA1 pyramidal neurons showing control-, LPS-, DHA- and LPS + DHA-treated dendritic spine morphologies. In the presence of LPS, there is a decrease in spine densities. Higher LPS concentration (1 $\mu \mathrm{g} / \mathrm{ml})$ causes a more pronounced spine decrease compared to lower concentration of LPS (100 ng/ml). With DHA alone, there is no difference in dendritic spine morphologies compared to control. If the LPS-treated cultures are pre-incubated with DHA, no spine loss is observed. Lower (100 ng/ml) or higher LPS $(1 \mu \mathrm{g} / \mathrm{ml})$ concentrations do not differ in their response to DHA pre-treatment. Scale bar $2 \mu \mathrm{m}$. B Dendritic spine density under various treatments in CA1 pyramidal neurons. ${ }^{*} p<0.05$. 
DHA: $1.59 \pm 0.083$ spines $/ \mu \mathrm{m}, n=18$ cells; $p>0.05$ ]. It is interesting to note that even at high concentrations of LPS treatment, DHA successfully protected the damaging effects on synaptic structures caused by inflammation.

As dendritic spine morphologies can influence the integrity of synaptic transmission, we examined basic synaptic transmission of the CA1 pyramidal neurons following LPS and DHA treatments in organotypic slice cultures. To assess the functional impact of spine loss, we recorded spontaneous AMPA-mediated-mEPSC in order to study the strength of the CA3-CA1 excitatory synapses. We found that with LPS $(1 \mu \mathrm{g} / \mathrm{ml})$ treatment, there was a significant increase in the IEI (Figure 6; control: $316.20 \pm 27.08 \mathrm{~ms}, n=11$ cells; LPS: $410.54 \pm 65.53$ ms, $n=9$ cells; $\left.{ }^{*} p<0.05\right)$ with no change in mEPSC amplitude (Figure 6; control: $14.76 \pm 0.86 \mathrm{pA}$; DHA: $15.68 \pm 1.33 \mathrm{pA}$; LPS: $13.68 \pm 1.63 \mathrm{pA}$; LPS + DHA: $16.06 \pm 2.43 \mathrm{~ms} ; p>0.05)$. An increase in IEI following LPS treatment indicated that functional synapses were lost, as the occurrence of basal synaptic events had decreased. These changes in IEI, accompanied with the dendritic spine loss following LPS treatment, signified that in the LPS model of neuroinflammation, changes in the microglial activation state could negatively impact synaptic transmission. However, pre-treatment of the cultures with DHA prior to the addition of LPS successfully prevented the IEI increase associated with LPS treatment alone (Figure 6; DHA: $313.40 \pm 38.89 \mathrm{~ms}, n=8$ cells; LPS + DHA: $289.16 \pm 45.58 \mathrm{~ms}, n=12$ cells; $p>0.05$ ). Hence, from these findings we conclude that DHA pre-treatment has the potential to prevent LPS-induced changes in microglia, including altered LB size distribution, mitochondrial function and expression of LB-associated protein levels (Figure 7). DHA prevented structural and functional synaptic alterations in CA1 pyramidal neurons induced by LPS treatment (Figure 7).

\section{Discussion and conclusions}

The findings from this study show that LPS causes profound microglia activation in organotypic and N9 microglia cultures. This is associated with marked changes in LB number and size distribution, accompanied with changes in CA1 synaptic structure and function. Interestingly, we found that DHA treatment prior to the LPS exposure prevented microglia hyperactivity and neural impairments in CA1 in organotypic hippocampal slices. These findings are in line with an enhanced production of proinflammatory biomarkers including cytokines and a preventive effect of DHA in the brain following systemic LPS administration [49].

It is well documented that microglia can exert both positive and negative effects on neurons depending on their activation state [50]. Mildly and transiently activated microglia do not exert marked effects on dendritic

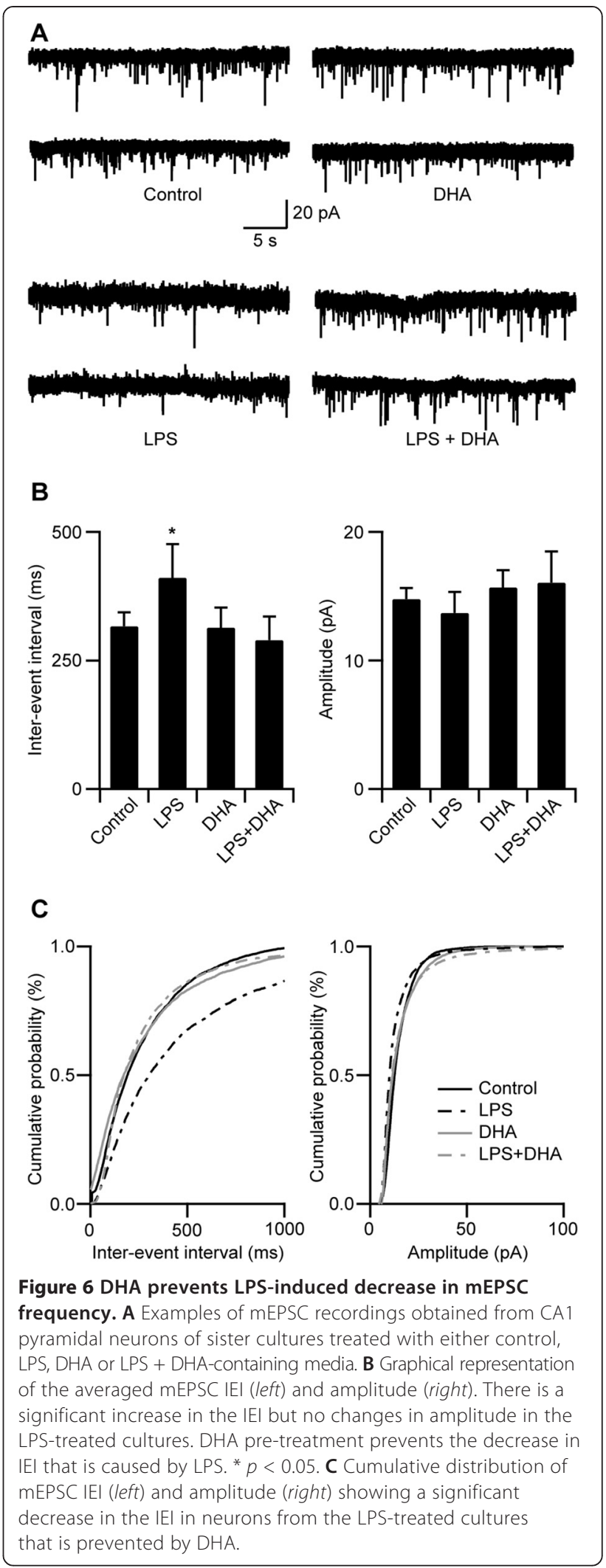




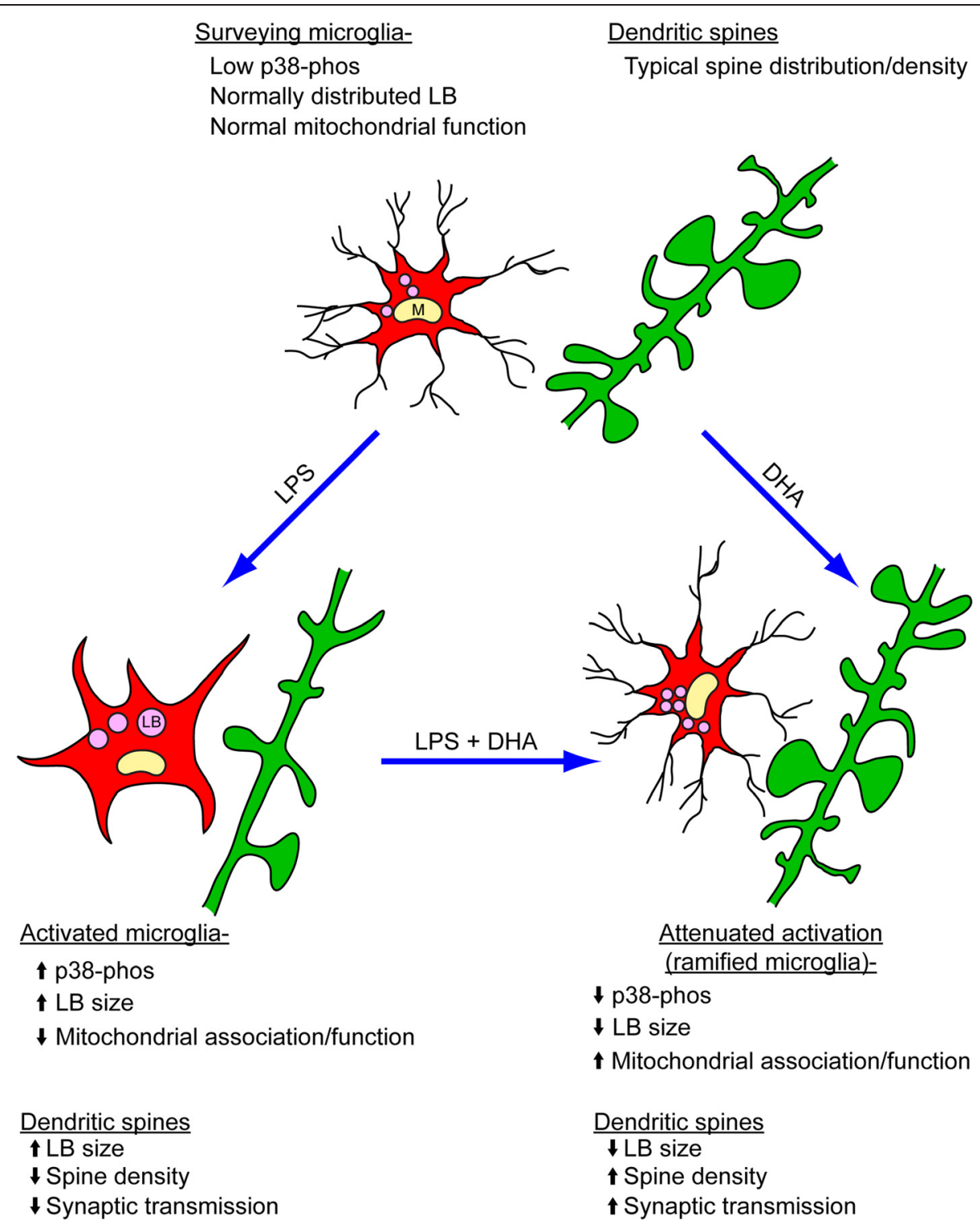

Figure 7 Summarizing schematic: DHA treatment prevents microglial activation, LB aggregation and dendritic spine loss. LPS causes microglial activation, nitric oxide release, p38 phosphorylation and increases in LB size, while it decreases dendritic spine densities in neurons. However, DHA treatment can prevent LPS-induced effects. DHA decreases nitric oxide release, p38 phosphorylation and LB size, and it restores dendritic spine densities.

spine morphologies because the numerous astrocytes within the vicinity of the neurons compensate for small imbalances between the trophic and inflammatory factors [13,51]. However, with a strong or chronic inflammatory stimulus, e.g., endotoxin LPS, the compensatory mechanisms fail in re-establishing cellular homeostasis in the brain [52-54]. As shown here, the status of activation of microglia is critical in their "synapse-sculpting" processes similar to what has been reported during neuronal circuitry development [55]. Hence, microglia hyperactivity as well as inappropriate tagging of synapses through the complement system is deleterious to synaptic structure and function [13,55-58].
In this study we have observed that exposure of hippocampal slices to high concentrations of LPS $(1 \mu \mathrm{g} / \mathrm{ml})$ induces loss of dendritic spines accompanied with the release of nitric oxide and formation of large LBs in neighboring microglia. LBs can be either protective or deleterious to the neuronal circuitry. We found LPS induced the formation of large LBs in microglia, which were reduced in size with DHA pretreatment prior to exposure to LPS. Large LBs formed in microglia upon LPS treatment showed only a small increase in perilipin2. Perilipin-2 is an integral membrane protein decorating the surface of LBs that is important for the structural 
stability of LBs $[46,59,60]$. It has been shown that perilipin-2 is recruited to the LB surface and acts as a key regulator of LB stability and biogenesis [44]. The very small elevation of perilipin-2 following LPS treatment in conjunction with the marked enlargement of LB size is suggestive of instability in the phospholipid membrane of LB [61]. Such a destabilization of LBs can negatively affect lipid compartmentalization within the cell and further worsen the oxidative stress caused by LPS exposure. Free radicals such as reactive oxygen species (ROS) and reactive nitrogen species (RNS) can interact with lipids and cause lipid peroxidation to produce extremely cytotoxic compounds, which could lead to the functional impairments [62]. We found that mitochondrial function was impaired in both glia and neurons after LPS treatment, and this was accompanied by nitric oxide release and impairments in excitatory synaptic functions and structure. Our results suggest that DHA exerts protective effects in both microglia and excitatory neurons by maintaining the optimal LB size and stability by upregulation of perilipin- 2 and preservation of spine morphologies. We hypothesize that the mechanisms implicated in these processes could be acting both directly on neurons and indirectly by first normalizing the biochemical changes and morphology in microglia, which then impact positively on neuronal circuitry in the hippocampal CA1 region. Although it is not fully elucidated, glial cells have the ability to produce pro-resolvin mediators, which could contribute to this positive effect [63]. In addition, DHA might modulate endocannabinoid signaling since both neurons and glia produce endocannabinoids and express endocannabinoid receptors that are implicated in neuroprotection [64].

Our studies showed that the total number of spines is preserved in CA1 pyramidal neurons in hippocampal organotypic cultures with pretreatment with DHA before LPS. DHA can directly affect the neurons through the activation of the G-protein coupled receptor, GPR120 $[65,66]$. DHA has also been reported to be highly enriched in synapses and plays an important role in the expression of many proteins found in the dendritic spines such as drebrin and postsynaptic density protein PSD95, both of which are essential for the integrity of excitatory synapses [67-69]. Indirect effects could be explained by DHA conversion into resolvins and protectins; these can attenuate inflammation through the downregulation of proinflammation cytokine production and an upregulation of the neurotrophin brain-derived neurotrophic factor (BDNF) [5,70-73]. It is well known that BDNF in physiological concentrations can improve synaptic circuitry [74]. In fact, it has been previously reported that elevated DHA levels in the brain can normalize BDNF levels in rat brain trauma [75]. Furthermore, the antiinflammatory effects of DHA could also be due to direct effects of DHA on the translocation of transcription factor NF- $\mathrm{kB}$ from the cytosol to the nucleus in microglia. Normalization NF$\kappa B$ activity by DHA could also contribute to an antiinflammatory effect by attenuation of proinflammatory cytokine gene transcription driven by a nuclear pool of NF- $k B$ (e.g., TNF $\alpha$ and IL-1 $\beta$ ) [76]. Finally, DHAinduced LB increases in number, but a decrease in LB size could be favorable for LB-mitochondria interaction and preservation of mitochondrial homeostasis in microglia and neurons. Mitochondrial integrity and homeostasis are required for maintenance of synaptic circuitry [77]. A close apposition of LBs and mitochondria, as we have found in DHA-treated microglial cells, would contribute to antiinflammatory effects of DHA in different ways. First, the close association between LBs and mitochondria may facilitate the coupling of triglyceride (TG) hydrolysis and promote ATP production in mitochondria. Second, it could contribute to an enrichment of non-peroxidized cardiolipins in mitochondria [78]. Cardiolipins are lipid components that make up about $20 \%$ of the mitochondrial inner membrane, and they are involved in the regulation of mitochondrial structure and function [79-81]. A reduction of peroxidized cardiolipin species by DHA has previously been shown to reduce or even prevent mitochondrial functional impairment [82]. The promotion of mitochondrial health is in line with our observed enhancement in mitochondrial function following DHA supplementation. Future studies should employ lipidomic analysis of organelles investigated in these models to reveal both early neurodegenerative changes and beneficial effects of DHA. Ideally, lipidomic studies should be extended to the analyses of specific regions and cell types of both the central and peripheral nervous system in humans with and without DHA supplementation [83]. Thus, uncovering the mechanisms involved in the direct effects of DHA on neurons and indirectly through regulation of glia in different brain structures to preserve synaptic circuitry clearly merits further investigations [69].

\section{Additional file}

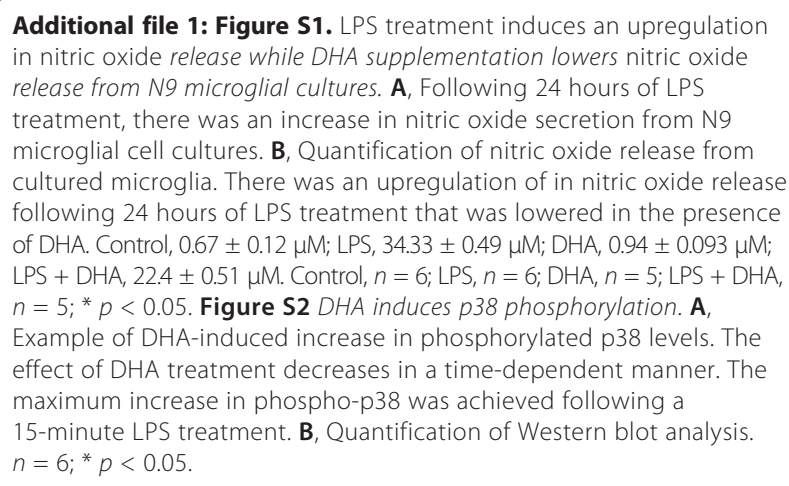




\section{Abbreviations}

DHA: Docosahexaenoic acid; LPS: Lipopolysaccharide; mEPSCs: Miniature excitatory postsynaptic currents; LBs: Lipid bodies; CD14: Cluster of differentiation 14; TLR4: Toll-like receptor 4; PI3-K: Phosphatidylinositol 3-kinase, FOXO1, Forkhead box protein O1; JNK: c-Jun N-terminal kinase; NFkB: Nuclear factor kappa-light-chain-enhancer of activated B cells; TG: Triglycerides; PC: Phosphatidylcholine; PE: Phosphatidylethanolamine; AMPA: 2-amino-3-(3-hydroxy-5-methyl-isoxazol-4-yl) Propanoic acid; PB: Phosphate buffer; MTT: 3-(4,5-dimethylthiazol-2-yl)-2,5-Diphenyltetrazolium bromide; TTX: Tetrodotoxin; IEl: Inter-event interval; Iba-1: Ionized calcium-binding adapter molecule-1.

\section{Competing interest}

The authors declare that they have no competing interests.

\section{Authors' contributions}

RAM and DM designed the experiments. PKYC, RAM and DM wrote the drafts and edited the final version of the manuscript. PKYC performed all experiments with hippocampal organotypic cultures, analyzed the data and prepared the figures. AK performed experiments with primary cultures and data analyses and prepared the corresponding figures. All authors read and approved the final manuscript.

\section{Acknowledgements}

Confocal image analysis of microglia and neurons for this manuscript was performed in the McGill University Life Sciences Complex Imaging Facility. Purchase of equipment in the facility was made possible with funding from the Canadian Foundation for Innovation (CFI) and the Ministère du Développement économique, innovation et exportation Québec (MDEIE). DM was supported by the Canadian Institutes for Health Research (CIHR MOP 119425) Alzheimer's Society of Canada. RAM was supported by Canadian Institutes for Health Research (CIHR MOP 133611) NSERC Discovery grant and the Alzheimer's Society of Canada. PKYC and AK were supported in part by a Graduate Excellence Fellowship from McGill University. The authors thank Dr. J. Diamond for editorial assistance of the drafted manuscript. We also thank François Charron and Andrew Lake for their excellent technical assistance.

\section{Author details}

'Department of Pharmacology and Therapeutics, McGill University, McIntyre Medical Building, Room 1314, 3655 Promenade Sir William Osler, Montreal, QC H3G 1Y6, Canada. ${ }^{2}$ Department of Pharmacology \& Therapeutics, Bellini Life Science Complex, McGill University, Room 167, 3649 Promenade Sir-William-Osler, Montreal, QC H3G OB1, Canada.

\section{Received: 4 August 2014 Accepted: 11 January 2015}

\section{Published online: 22 February 2015}

\section{References}

1. Salter Michael W, Beggs S. Sublime microglia: expanding roles for the guardians of the CNS. Cell. 2014;158:15-24.

2. Galland L. Diet and inflammation. Nutr Clin Pract. 2010;25:634-40.

3. Dinarello CA. Anti-inflammatory agents: present and future. Cell. 2010;140:935-50.

4. Raederstorff D, Pantze M, Bachmann H, Moser U. Anti-inflammatory properties of docosahexaenoic and eicosapentaenoic acids in phorbol-ester-induced mouse ear inflammation. Int Arch Allergy Immunol. 1996;111:284-90.

5. Hong S, Gronert K, Devchand PR, Moussignac R-L, Serhan CN. Novel docosatrienes and $17 \mathrm{~s}$-resolvins generated from docosahexaenoic acid in murine brain, human blood, and glial cells: autocoids in anti-inflammation. J Biol Chem. 2003;278:14677-87.

6. Innis SM. Dietary (n-3) fatty acids and brain development. J Nutr. 2007;137:855-9.

7. Dyall SC, Michael-Titus AT. Neurological benefits of omega-3 fatty acids. Neuromolecular Med. 2008;10:219-35.

8. Hartmann T, van Wijk N, Wurtman RJ, Olde Rikkert MGM, Sijben JWC, Soininen $\mathrm{H}$, et al. A nutritional approach to ameliorate altered phospholipid metabolism in Alzheimer's disease. J Alzheimer's Dis. 2014;41:715-7.

9. Cansev M, Wurtman RJ. Chronic administration of docosahexaenoic acid or eicosapentaenoic acid, but not arachidonic acid, alone or in combination with uridine, increases brain phosphatide and synaptic protein levels in gerbils. Neuroscience. 2007;148:421-31.
10. Cole GM, Ma Q-L, Frautschy SA. Omega-3 fatty acids and dementia. Prostaglandins Leukot Essent Fatty Acids. 2009;81:213-21.

11. Berson EL, Rosner B, Sandberg MA, Weigel-DiFranco C, Moser A, Brockhurst $\mathrm{RJ}$, et al. Clinical trial of docosahexaenoic acid in patients with retinitis pigmentosa receiving vitamin a treatment. Arch Ophthalmol. 2004;122:1297-305.

12. Quinn JF, Raman R, Thomas RG, Yurko-Mauro K, Nelson EB, Van Dyck C, et al. Docosahexaenoic acid supplementation and cognitive decline in Alzheimer disease: a randomized trial. JAMA. 2010;304:1903-11.

13. Kettenmann H, Kirchhoff F, Verkhratsky A. Microglia: new roles for the synaptic stripper. Neuron. 2013;77:10-8.

14. Hughes V. Microglia: the constant gardeners. Nature. 2012;485:570-2.

15. Hughes MM, Field RH, Perry VH, Murray $\mathrm{CL}$, Cunningham C. Microglia in the degenerating brain are capable of phagocytosis of beads and of apoptotic cells, but do not efficiently remove prpsc, even upon LPS stimulation. Glia. 2010;58:2017-30.

16. Davalos D, Grutzendler J, Yang G, Kim JV, Zuo Y, Jung S, et al. ATP mediates rapid microglial response to local brain injury in vivo. Nat Neurosci. 2005;8:752-8.

17. Nimmerjahn A, Kirchhoff F, Helmchen F. Resting microglial cells are highly dynamic surveillants of brain parenchyma in vivo. Science. 2005;308:1314-8.

18. Tremblay M-Ë, Lowery RL, Majewska AK. Microglial interactions with synapses are modulated by visual experience. PLoS Biol. 2010;8:e1000527.

19. Wake H, Moorhouse AJ, Jinno S, Kohsaka S, Nabekura J. Resting microglia directly monitor the functional state of synapses in vivo and determine the fate of ischemic terminals. J Neurosci. 2009;29:3974-80.

20. Paolicelli R, Bolasco G, Pagani F, Maggi L, Scianni M, Panzanelli P, et al. Synaptic pruning by microglia is necessary for normal brain development. Science. 2011;333:1456-8.

21. Tremblay M-Ė, Stevens B, Sierra A, Wake H, Bessis A, Nimmerjahn A. The role of microglia in the healthy brain. J Neurosci. 2011;31:16064-9.

22. Nakamura Y, Si QS, Kataoka K. Lipopolysaccharide-induced microglial activation in culture: temporal profiles of morphological change and release of cytokines and nitric oxide. Neurosci Res. 1999;35:95-100.

23. Hanisch U-K. Microglia as a source and target of cytokines. Glia. 2002:40:140-55.

24. Hanisch U-K, Johnson TV, Kipnis J. Toll-like receptors: roles in neuroprotection? Trends Neurosci. 2008:31:176-82.

25. Martin S, Parton RG. Lipid droplets: a unified view of a dynamic organelle. Nat Rev Mol Cell Biol. 2006;7:373-8.

26. Farese RV, Walther TC. Lipid droplets finally get a little r-e-s-p-e-c-t. Cell. 2009;139:855-60.

27. Murphy S, Martin S, Parton RG. Lipid droplet-organelle interactions; sharing the fats. BBA - Mol Cell Biol L. 2009;1791:441-7.

28. Lecchi C, Invernizzi G, Agazzi A, Modina S, Sartorelli P, Savoini G, et al. Effects of EPA and DHA on lipid droplet accumulation and mRNA abundance of pat proteins in caprine monocytes. Res Vet Sci. 2013;94:246-51.

29. McKinney RA. Physiological roles of spine motility: development, plasticity and disorders. Biochem Soc Trans. 2005;33:1299-302.

30. McKinney RA. Excitatory amino acid involvement in dendritic spine formation, maintenance and remodelling. J Physiol. 2010;588:107-16.

31. McKinney RA, Thompson SM. Glutamate regulation of dendritic spine form and function. In: Squire LR, editor. Encyclopedia of neuroscience. Oxford: Academic; 2009. p. 905-11.

32. Colgan LA, Yasuda R. Plasticity of dendritic spines: subcompartmentalization of signaling. Annu Rev Physiol. 2014;76:365-85.

33. Sala C, Segal M. Dendritic spines: the locus of structural and functional plasticity. Physiol Rev. 2014;94:141-88.

34. Harris KM, Weinberg RJ. Ultrastructure of synapses in the mammalian brain. Cold Spring Harb Perspect Biol. 2012;4:1-30.

35. Matsuzaki M, Honkura N, Ellis-Davies GCR, Kasai H. Structural basis of long-term potentiation in single dendritic spines. Nature. 2004:429:761-6.

36. Bourne J, Harris KM. Do thin spines learn to be mushroom spines that remember? Curr Opin Neurobiol. 2007;17:381-6.

37. Rochefort NL, Konnerth A. Dendritic spines: from structure to in vivo function. Journal Article. 2012;13:699-708.

38. Lai K-O, Ip NY. Structural plasticity of dendritic spines: the underlying mechanisms and its dysregulation in brain disorders. BBA - Mol Basis Dis. 2013;1832:2257-63. 
39. Pozueta J, Lefort R, Shelanski ML. Synaptic changes in Alzheimer's disease and its models. Neuroscience. 2013;251:51-65.

40. Nimchinsky EA, Sabatini BL, Svoboda K. Structures and function of dendritic spines. Annu Rev Physiol. 2002;64:313-53.

41. Gähwiler BH, Capogna M, Debanne D, McKinney RA, Thompson SM. Organotypic slice cultures: a technique has come of age. Trends Neurosci. 1997;20:471-7.

42. Chang PKY, Boridy S, McKinney RA, Maysinger D. Letrozole potentiates mitochondrial and dendritic spine impairments induced by $\beta$-amyloid. J Aging Res. 2013;2013:1-11.

43. Bulankina AV, Deggerich A, Wenzel D, Mutenda K, Wittmann JG, Rudolph MG, et al. TIP47 functions in the biogenesis of lipid droplets. J Cell Biol. 2009;185:641-55.

44. Imamura M, Inoguchi T, Ikuyama S, Taniguchi S, Kobayashi K, Nakashima N et al. ADRP stimulates lipid accumulation and lipid droplet formation in murine fibroblasts. Am J Physiol Endocrinol Metab. 2002;283:E775-83.

45. Feingold KR, Kazemi MR, Magra AL, McDonald CM, Chui LG, Shigenaga JK, et al. ADRP/ADFP and Mal1 expression are increased in macrophages treated with tlr agonists. Atherosclerosis. 2010;209:81-8.

46. Khatchadourian A, Bourque SD, Richard VR, Titorenko VI, Maysinger D. Dynamics and regulation of lipid droplet formation in lipopolysaccharide (LPS)-stimulated microglia. BBA - Mol Cell Biol L. 2012;1821:607-17.

47. Jägerström S, Polesie S, Wickström $Y$, Johansson BR, Schröder HD, Højlund K, et al. Lipid droplets interact with mitochondria using Snap23. Cell Biol Int. 2009;33:934-40.

48. Goodman JM. The gregarious lipid droplet. J Biol Chem. 2008;283:28005-9.

49. Orr SK, Trépanier M-O, Bazinet RP. N-3 polyunsaturated fatty acids in animal models with neuroinflammation. Prostaglandins Leukot Essent Fatty Acids (PLEFA). 2013;88:97-103.

50. Aguzzi A, Barres BA, Bennett ML. Microglia: scapegoat, saboteur, or something else? Science. 2013;339:156-61

51. Kettenmann H, Hanisch U-K, Noda M, Verkhratsky A. Physiology of microglia. Physiol Rev. 2011;91:461-553.

52. Goings GE, Kozlowski DA, Szele FG. Differential activation of microglia in neurogenic versus non-neurogenic regions of the forebrain. Glia. 2006;54:329-42.

53. Hanisch U-K, Kettenmann H. Microglia: active sensor and versatile effector cells in the normal and pathologic brain. Nat Neurosci. 2007;10:1387-94.

54. Gurley C, Nichols J, Liu S, Phulwani NK, Esen N, Kielian T. Microglia and astrocyte activation by toll-like receptor ligands: modulation by PPAR- agonists. PPAR Res. 2008;2008:15.

55. Schafer DP, Lehrman EK, Stevens B. The "quad-partite" synapse: microglia-synapse interactions in the developing and mature cns. Glia. 2013;61:24-36.

56. Schafer DP, Lehrman EK, Kautzman AG, Koyama R, Mardinly AR, Yamasaki R, et al. Microglia sculpt postnatal neural circuits in an activity and complement-dependent manner. Neuron. 2012;74:691-705.

57. Stephan AH, Barres BA, Stevens B. The complement system: an unexpected role in synaptic pruning during development and disease. Annu Rev Neurosci. 2012;35:369-89.

58. Stevens B, Allen NJ, Vazquez LE, Howell GR, Christopherson KS, Nouri N, et al. The classical complement cascade mediates CNS synapse elimination. Cell. 2007;131:1164-78.

59. Guo Y, Cordes KR, Farese RV, Walther TC. Lipid droplets at a glance. J Cell Sci. 2009;122:749-52.

60. Khatchadourian A, Maysinger D. Lipid droplets: their role in nanoparticle-induced oxidative stress. Mol Pharm. 2009;6:1125-37.

61. Yang H, Galea A, Sytnyk V, Crossley M. Controlling the size of lipid droplets: lipid and protein factors. Curr Opin Cell Biol. 2012;24:509-16.

62. Chen CT, Trepanier M-O, Hopperton KE, Domenichiello AF, Masoodi M, Bazinet RP. Inhibiting mitochondrial [beta]-oxidation selectively reduces levels of nonenzymatic oxidative polyunsaturated fatty acid metabolites in the brain. J Cereb Blood Flow Metab. 2014;34:376-9.

63. Serhan CN. Pro-resolving lipid mediators are leads for resolution physiology. Nature. 2014;510:92-101.

64. Lafourcade M, Larrieu T, Mato S, Duffaud A, Sepers M, Matias I, et al. Nutritional omega-3 deficiency abolishes endocannabinoid-mediated neuronal functions. Nat Neurosci. 2011;14:345-50.

65. Oh DY, Talukdar S, Bae EJ, Imamura T, Morinaga H, Fan W, et al. GPR120 is an omega-3 fatty acid receptor mediating potent anti-inflammatory and insulin-sensitizing effects. Cell. 2010;142:687-98.
66. Talukdar S, Olefsky JM, Osborn O. Targeting GPR120 and other fatty acid-sensing gpcrs ameliorates insulin resistance and inflammatory diseases. Trends Pharmacol Sci. 2011:32:543-50.

67. Calon F, Lim GP, Yang F, Morihara T, Teter B, Ubeda O, et al Docosahexaenoic acid protects from dendritic pathology in an Alzheimer's disease mouse model. Neuron. 2004:43:633-45.

68. Calon F, Lim GP, Morihara T, Yang F, Ubeda O, Salem N, et al. Dietary n-3 polyunsaturated fatty acid depletion activates caspases and decreases nmda receptors in the brain of a transgenic mouse model of Alzheimer's disease. Eur J Neurosci. 2005;22:617-26.

69. Bazinet RP, Laye S. Polyunsaturated fatty acids and their metabolites in brain function and disease. Nat Rev Neurosci. 2014;15:771-85.

70. Rao JS, Ertley RN, Lee HJ, DeMar Jr JC, Arnold JT, Rapoport SI, et al. N-3 polyunsaturated fatty acid deprivation in rats decreases frontal cortex bdnf via a p38 MAPK-dependent mechanism. Mol Psychiatry. 2006;12:36-46.

71. Bazan NG. Omega-3 fatty acids, pro-inflammatory signaling and neuroprotection. Curr Opin Clin Nutr Metab Care. 2007;10:136-41.

72. Cole GM, Frautschy SA. DHA may prevent age-related dementia. J Nutr. 2010;140:869-74.

73. Picq M, Chen P, Perez M, Michaud M, Véricel E, Guichardant M, et al. DHA metabolism: targeting the brain and lipoxygenation. Mol Neurobiol. 2010;42:48-51.

74. Bibel M, Barde Y-A. Neurotrophins: key regulators of cell fate and cell shape in the vertebrate nervous system. Genes Dev. 2000;14:2919-37.

75. Wu A, Ying Z, Gomez-Pinilla F. Dietary omega-3 fatty acids normalize BDNF levels, reduce oxidative damage, and counteract learning disability after traumatic brain injury in rats. J Neurotrauma. 2004;21:1457-67.

76. Zhao M, Zhou A, Xu L, Zhang X. The role of TLR4-mediated PTEN/PI3K/AKT/ NF-KB signaling pathway in neuroinflammation in hippocampal neurons. Neuroscience. 2014;269:93-101.

77. Sheng Z-H, Cai Q. Mitochondrial transport in neurons: impact on synaptic homeostasis and neurodegeneration. Nat Rev Neurosci. 2012;13:77-93.

78. Tyurina YY, Poloyac SM, Tyurin VA, Kapralov AA, Jiang J, Anthonymuthu TS, et al. Mitochondrial pathway for biosynthesis of lipid mediators. Nat Chem. 2014;6:542-52.

79. Flis W, Daum G. Lipid transport between the endoplasmic reticulum and mitochondria. Cold Spring Harb Perspect Biol. 2013;5:1-22.

80. Cosentino K, García-Sáez AJ. Mitochondrial alterations in apoptosis. Chem Phys Lipids. 2014;181:62-75.

81. Ren M, Phoon CKL, Schlame M. Metabolism and function of mitochondrial cardiolipin. Prog Lipid Res. 2014;55:1-16.

82. Chu CT, Ji J, Dagda RK, Jiang JF, Tyurina YY, Kapralov AA, et al. Cardiolipin externalization to the outer mitochondrial membrane acts as an elimination signal for mitophagy in neuronal cells. Nat Cell Biol. 2013;15:1197-205.

83. Mapstone M, Cheema AK, Fiandaca MS, Zhong X, Mhyre TR, MacArthur LH, et al. Plasma phospholipids identify antecedent memory impairment in older adults. Nat Med. 2014;20:415-8.

\section{Submit your next manuscript to BioMed Central and take full advantage of:}

- Convenient online submission

- Thorough peer review

- No space constraints or color figure charges

- Immediate publication on acceptance

- Inclusion in PubMed, CAS, Scopus and Google Scholar

- Research which is freely available for redistribution 